\title{
Evaluation of Curcumin Capped Copper Nanoparticles as Possible Inhibitors of Human Breast Cancer Cells and Angiogenesis: a Comparative Study with Native Curcumin
}

\author{
Sonali Kamble, ${ }^{1}$ Bhimashankar Utage, ${ }^{2}$ Pratima Mogle, ${ }^{3}$ Rahul Kamble, ${ }^{3}$ Shrikant Hese, ${ }^{3}$ \\ Bhaskar Dawane, ${ }^{3}$ and Rajesh Gacche ${ }^{1,4}$
}

\begin{abstract}
Received 4 July 2015; accepted 13 October 2015; published online 21 October 2015
Abstract. Synthesis of metal nanoparticles for improving therapeutic index and drug delivery is coming up as an attractive strategy in the mainstream of cancer therapeutic research. In the present study, curcumincapped copper nanoparticles (CU-NPs) were evaluated as possible inhibitors of in vivo angiogenesis, proangiogenic cytokines involved in promoting tumor angiogenesis along with inhibition of cell proliferation and migration of breast cancer cell line MDA-MB-231. The antiangiogenic potential was assessed using in vivo chorioallantoic membrane (CAM) model. 3-(4, 5-Dimethylthiazol-2-yl)-2, 5-diphenyltetrazolium bromide (MTT)-based cytotoxicity assay was used to assess the effect of CU-NPs against proliferation of breast cancer cell line. The wound healing migration assay was used to evaluate the effects of CU-NPs on the migration ability of breast cancer cell line. Native curcumin (CU) was used as a reference compound for comparison purpose. The result of the present investigation indicates that CU-NPs could not demonstrate impressive antiangiogenic or anticancer activities significantly as compared to native CU. The possible mechanisms of experimental outcomes are discussed in the light of the methods of nanoparticle synthesis in concert with the current state of the art literature.
\end{abstract}

KEY WORDS: angiogenesis; breast cancer; chorioallantoic membrane; curcumin; nanoparticles.

\section{INTRODUCTION}

Breast cancer is the most frequent cancer worldwide and the second leading cause of cancer-related death among females in the world (1). The global concern of breast cancer exceeds all other cancers and the incidence rates of breast cancer are increasing (2). Breast cancer in women has been a gloom issue in the medical history for decades (3). Consequently, to address this challenge, there has been a growing interest towards the nanotechnology-based approaches for the development of targeted drug delivery system (4). In the recent past, synthetic preparation and study of nanoparticles has gained a central importance in biomedical research owing to its wide range of potential therapeutic applications (5). Nanotechnology is constantly being encouraged to overcome numerous limitations of conventional drug delivery systems since the latter fails to efficiently distinguish between cancerous and normal cells (6). Targeting strategies of nanoparticles towards the cancerous tissues have

\footnotetext{
$\overline{{ }^{1} \text { School of Life Sciences, Swami Ramanad Teerth Marathwada }}$ University, Nanded, 431 606, MS, India.

${ }^{2}$ National Centre for Cell Sciences, University of Pune Campus, Pune, 411007, MS, India.

${ }^{3}$ School of Chemical Sciences, Swami Ramanad Teerth Marathwada University, Nanded, 431 606, MS, India.

${ }^{4}$ To whom correspondence should be addressed. (e-mail: rngacche@rediffmail.com)
}

concentrated on passive and active targeting. Several tumors possess deficient vasculature as well as poor lymphatic drainage due to the rapid growth of solid tumors. In case of passive targeting, noble metal nanoparticles can discharge into the tumor stroma through the fenestrations of the angiogenic vasculature, signifying targeting by improved permeation and retention and thus accumulation at the tumor site (7). Moreover, the use of hydrophilic molecules, such as polyethylene glycol (PEG), can also significantly enhance their solubility, facilitate evading macrophage-mediated uptake and, therefore, evade exclusion from the fundamental circulation plus protect their carriers from enzymatic degradation when used in vivo (8). For active targeting, nanoparticles can be easily improved with a broad range of biological moieties, such as antibodies, peptides, and DNA or RNA, to distinctively target extracellular and intracellular receptors (8). The use of nanoparticles functionalized with several antibodies, such as monoclonal antibodies, has been depicted to effectively target particular cell surface proteins or receptors on cancer cells and formerly direct their antitumor action, inducing tumor cell death with least damage to healthy cells (9).

Among the distinct nanoparticles that have been researched for remedial purposes against cancer are magnetic nanoparticles (10). Much attention has been paid to the synthesis of metal nanoparticles because of their unique physical properties such as high surface-to-volume ratio, ease of synthesis, facile surface chemistry, and broad optical properties. The chemical properties such as enhanced catalytic activity 
formulate them suitable for drug delivery and targeting (11). Because of their larger surface area, metal nanoparticles demonstrate several precise physicochemical properties that make them useful for the treatment of cancer such as their cytotoxicity after interaction with cancer cells. The antitumor mechanism of metal nanoparticles could work through the generation of reactive oxygen species, apoptosis, and necrosis (12). Utilization of metal nanoparticles for killing of cancer cells seems to be relative with the nature and properties of metal nanoparticles. Several mechanisms of anticancer activities of metal nanoparticles have been proposed which includes hyperthermia, photothermal effect, and reactive oxygen species generation. The efficacy of nanoparticles also depends on the nature of the metal, size and shape of the nanoparticle, and its surface properties (13).

As per definition, nanomaterials are materials or totals of materials in the size scope of 1-100 nm (14). But in accordance with the consideration of the size and diameter of nanoparticles, they can be further categorized as fine particle which has the range of 100 to $2500 \mathrm{~nm}$ or ultrafine particles having the size of 1 to $100 \mathrm{~nm}(15)$.

Naturally occurring therapeutically active biomolecules gained an immense attention for the synthesis of metal nanoparticles (16). Among a variety of functional food ingredients, several polyphenols have demonstrated as anticancer agents and curcumin is one of them and known for its potent anticancer activity (17). Curcumin is the active ingredient isolated from the rhizomes of turmeric (Curcuma longa) (18). Curcumin is known for its intense antineoplastic movement against various tumors, including breast, prostate, and colon malignancies (19). The chemopreventive feasibility of curcumin in all phases of carcinogenesis has gotten huge consideration on account of its low nonspecific danger to normal cells (20). Curcumin is equipped for meddling with a few biochemical pathways included in the proliferation and survival of malignancy cells by straightforwardly and in an ambiguous way tying to distinctive targets (21). Curcumin has been demonstrated as a blocker of $N F-\kappa B$ activation, which has been connected with proliferation, invasion, and inhibition of apoptosis (22). Curcumin has long been perceived to have antiviral, antibacterial, antioxidant, anti-inflammatory, antiproliferative, and antiangiogenic exercises (23).

Nevertheless, the leading issue restricting the exploitation of its conceivably valuable remedial impacts is its low bioavailability (24). Various methodologies have been examined to deal with the solubility and bioavailability limits of curcumin and to enhance its solubility and to convey it to cancer cells (25). Early clinical studies imply that nanoparticles are advantageous for cancer therapy attributable to its capability of more focused localization in the tumor microenvironment (26). Therefore, to build up a curcumin molecule with superior bioavailability, different progressions in the preparations of curcumin nanoparticles have been further investigated for the application in cancer therapeutics (27). A few techniques like encapsulation and transportation of curcumin have likewise been investigated to improve bioavailability and to accomplish the most response of this potentially useful molecule (28). Alongside the nanoparticles, a scope of diverse nanovehicles, for example, liposomes, micelles, dendrimers, nanogels, and exosomes, has been utilized to encapsulate curcumin for enhanced bioavailability (29).
In the present investigation, we have synthesized curcumin-capped copper nanoparticles. The comparative anticancer potential of curcumin (CU) and curcumin-capped copper nanoparticles (CU-NPs) was evaluated by 3-(4, 5-dimethylthiazol-2-yl)-2, 5-diphenyltetrazolium bromide (MTT)based cytotoxicity assay and cell migration assay against human breast cancer cell lines. The antiangiogenic activity of CU and CU-NPs was tested using Human Angiogenesis I ELISA Strip Kit for profiling eight cytokines and in vivo chorioallantoic membrane model. The results of the present study demonstrate that, among CU and CU-NPs, CU was found to be having an effective anticancer potential as well as the effective inhibitor of angiogenesis as compared to CU-NPs. A discourse on limitations of synthetic methodology and the related biological activity of CU-NPs might act as a ready reference for designing and developing novel nanoparticles of therapeutic significance.

\section{MATERIALS AND METHODS}

Curcumin was purchased from HiMedia Laboratories, Mumbai, (MS), India. Leibovitz's L-15 medium was purchased from $\mathrm{GIBCO}^{\mathrm{TM}}$ Invitrogen (Grand Island, NY, USA). MTT and fetal bovine serum (FBS) were procured from Sigma-Aldrich (St Louis, MO, USA). Human Angiogenesis I ELISA Strip Kit was purchased from Signosis, Inc (Santa Clara, CA, USA). Fertilized chicken eggs were purchased from the local market at Nanded City (MS), and breast cancer cell line MDA-MB-231 was obtained from the National Centre for Cell Sciences (NCCS), Pune (MS), India. All other chemicals, solvents, and reagents used were of analytical grade and were procured from commercial sources.

\section{Cell Culture}

Human breast cancer cell line MDA-MB-231 free from any bacterial and fungal contamination was cultured in Leibovitz's L-15 medium, supplemented with $10 \%$ heatinactivated FBS, $2 \mathrm{mM}$ glutamine, and without any antibiotics. Cells were maintained in an incubator at $37^{\circ} \mathrm{C}$ with $100 \%$ air before performing experiments (30).

\section{Synthesis of CU-NPs}

The Creighton method was used for the synthesis of nanoparticles (31). The synthesis of CU-NPs was carried out by the addition of curcumin $(2 \mathrm{mM})$ in $10-15 \mathrm{ml}$ of alcoholic solvent, followed by adding an aqueous solution of $0.002 \mathrm{mg}$ of $\mathrm{CuSO}_{4}$ with continuous stirring. Subsequently, the aqueous $\mathrm{NaBH}_{4}$ was added within 20-30 min until effervesces stops. The resulting solution was then diluted with water and, finally, filtered and dried.

\section{Characterization of CU-NPs}

\section{X-ray Diffraction Studies}

An X-ray diffraction (XRD) measurement of CU-NPs was performed using Bruker D8 Advance diffractometer (Bruker AXS, Karlsruhe, Germany). 
Fourier Transforms Infrared Analysis

CU-NPs were further characterized by Fourier transform infrared (FTIR) analysis. An IR spectrum was recorded as $\mathrm{KBr}$ pellets on FTIR Shimadzu spectrophotometer (Shimadzu, Japan 8400s) and PerkinElmer Spectrum version 100306 at Vishnu Chemical Pvt. Ltd., Hyderabad.

\section{UV-Visible Spectroscopy}

The progress and formation of CU-NPs was confirmed by UV-vis spectroscopy. The UV-visible absorption spectrum of CU-NPs was recorded in the wavelength region $200-700 \mathrm{~nm}$ using a UV-vis spectrophotometer (Shimadzu, Japan UV 1601).

\section{Scanning Electron Microscopy Analysis}

The morphological analysis of CU-NPs was carried out at STIC, Cochin University, Kerala, India, by using the scanning electron microscope JEOL model JSM-6390LV, USA.

\section{Nanoparticle Size Measurement by Nanoparticle Tracking and Analysis System (NanoSight Ltd, UK)}

The nanoparticle size was measured using Nanoparticle Tracking and Analysis (NTA) system (NanoSight Ltd, UK). The operational settings were carried out as per the manufacturer manual. The sample was diluted in ultrapure water to achieve the particle concentration of $10^{7}-10^{9} / \mathrm{ml}$. The calibrated sample was injected into LM 20 sample laser module (sample holder) by sterile syringes (32). The particles present in the liquid sample at standard temperature and viscosity possess the Brownian motion; the NTA software calculates the size of particles by tracking and analyzing the motion of individual particles under laser light illumination. The NTA 2.3 software measured the diffraction of laser light by a particle and processed and generated the data. The data are generated in terms of the mean (average particle size measured) and mode (most frequently observed). The values obtained by processing the sample were recorded and the modal value (most frequent particle size) was taken as a size of the nanoparticle. In NTA, the Stokes-Einstein equation is the basis for calculation of particle size (33).

\section{Chorioallantoic Membrane Assay}

The chorioallantoic membrane (CAM) assay was performed in an identical manner as depicted by (34). The fertilized chicken eggs were purchased from local markets at Nanded City, and then the eggs were cleaned for the disinfection. Eggs were kept in a humidified incubator at $37^{\circ} \mathrm{C}$. The eggs were positioned in a horizontal position and rotated several times. Egg development and morphology were analyzed with the help of egg Candler. On the ninth day of incubation, the eggs were opened on the snub side and a $1 \times 1 \mathrm{~cm}$ window was cut into the eggshell. The individual concentrations $(5,15,25 \mu \mathrm{M}$, respectively) of CU and CU-NPs prepared in dimethyl sulfoxide (DMSO, $0.05 \%, v / v)$ were applied $(20 \mu \mathrm{l} / \mathrm{disc})$ onto sterile glass discs $(10 \mathrm{~mm})$ separately and permitted to dry under laminar air flow conditions. The discs loaded with samples were inverted and applied over the CAM surface of 10-day-old embryos through the windows. Phosphate buffer saline (PBS) was utilized as a control. The windows were sealed with tape and the eggs were reincubated in a humidified incubator at $37^{\circ} \mathrm{C}$. After 2 days of incubation, the CAMs were harvested and the vessels meeting the glass disc were counted under an Olympus make SZ 61TR Zoom Trinocular Microscope. The antiangiogenic effect was expressed using the equation $1-T / C$, where $T$ indicates the no. of blood vessels intersecting the disc treated with samples, while $C$ indicates the no. of blood vessels intersecting the disc in control. The results obtained were expressed in percent values.

The control and treated CAMs were digitized using an Olympus make SZ 61TR Zoom Trinocular Microscope attached with CCD camera and an image capturing software Pinnacle v.6.0.2 (build 152). The digitized CAMs were further analyzed using the image analysis software AngioQuant v 1.33 (a MATLAB-based software tool for quantification of angiogenesis) for the analysis of number, length, size, and the junctions of the tubule complexes.

\section{Assay for Inhibition of Pro-angiogenic Cytokines Using Hu- man Angiogenesis I ELISA Strip Kit}

The profiling of the inhibition of pro-angiogenic cytokines advancing tumor growth, such as tumor necrosis factor alpha $(\mathrm{TNF} \alpha)$, insulin-like growth factor 1 (IGF1), vascular endothelial growth factor (VEGF), interleukin 6 (IL-6), fibroblast growth factor-basic $(\mathrm{FGFb})$, transforming growth factor beta (TGF $\beta)$, epidermal growth factor (EGF), and leptin, was completed according to the manufacturer's manual guidelines (Signosis, Inc., 528 Weddell Drive, Suite 5, Sunnyvale, CA 94089). In short, the fixing film over the plate was evacuated and $100 \mu \mathrm{l}$ of standard, control, or sample was added to each well and incubated for $1 \mathrm{~h}$ at room temperature with gentle shaking. The contents were aspired from each well followed by washing the well by adding $200 \mu \mathrm{l}$ of $1 \mathrm{X}$ assay wash buffer. The process of washing was repeated for three times. After the last wash, the remaining liquid was removed by inverting the plate against the clean paper towels. Then, $100 \mu \mathrm{l}$ of diluted biotin-labeled antibody mixture-I was added to each well and incubated for $1 \mathrm{~h}$ at room temperature with gentle shaking. The contents were washed as described above. To each well, a $100 \mu \mathrm{l}$ of diluted streptavidin-HRP conjugate was added and incubated for $45 \mathrm{~min}$ at room temperature with gentle shaking. Again, the contents were washed as described above. A substrate $(100 \mu \mathrm{l})$ was added to each well and incubated for $25 \mathrm{~min}$, followed by the addition of stop solution $(50 \mu \mathrm{l})$. The change in color of the mixture from blue to yellow indicates the occurrence of reaction. The optical density of each well was recorded using Thermo make Automatic Ex-Microplate Reader (M 51118170) at $450 \mathrm{~nm}$ within $30 \mathrm{~min}$. The percent activity of the pro-angiogenic cytokines were calculated using the equation $1-T / C$, where $T$ is the absorbance of the test sample, while $C$ indicates the absorbance of the control sample. The results obtained were expressed in percentage.

\section{Cell Migration Assay}

Breast cancer cell (MDA-MB-231) migration was determined by using the wound healing assay as previously described (35). Briefly, $1 \times 10^{4}$ cells/well was seeded in 24 -well culture plates and incubated for $12 \mathrm{~h}$ with L-15 complete 


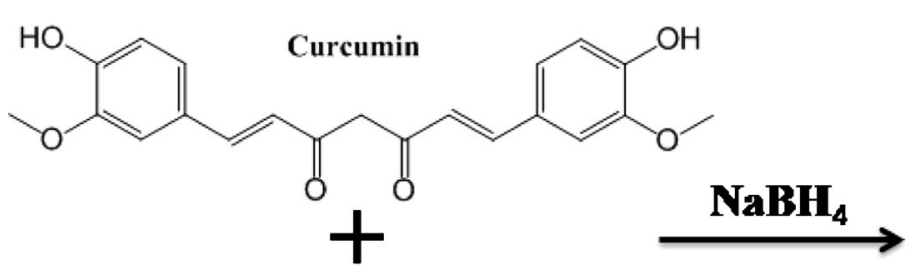

$\mathrm{CuSO}_{4}$

Scheme 1. Synthesis of CU-NPs

medium. Cell monolayer was wounded by scratching a line with sterile $10 \mu \mathrm{l}$ pipette tip. The detached cells were removed by washing the cell monolayer with PBS. Then different concentrations of $\mathrm{CU}$ and CU-NPs $(5,15,25 \mu \mathrm{M})$ containing complete medium were added. Photographs were taken at 0 and $12 \mathrm{~h}$ using an inverted Nikon microscope equipped with a digital camera.

\section{MTT Cell Proliferation Assay}

The effect of CU and CU-NPs on cell proliferation was examined by performing MTT assay described elsewhere (34). In brief, the MDA-MB-231 cells were seeded into 96-well culture plate containing L-15 cell culture medium at a density of $1 \times 10^{4}$ cells/well. Different concentrations of $\mathrm{CU}$ and CU-NPs were added separately. Cells were incubated for 24, 48, and $72 \mathrm{~h}$. After the treatment, cell culture medium was replaced with $50 \mu \mathrm{l}$ of $2 \mathrm{mg} / \mathrm{ml}$ of MTT and incubated at $37^{\circ} \mathrm{C}$ for $4 \mathrm{~h}$. The metabolically active cells reduce the yellow tetrazolium solution of MTT into formazan complex, which on addition of solvent turns in to a purple color. The formation of formazan product was recorded spectrophotometrically at $570 \mathrm{~nm}$. The data were plotted as the concentration of CU and CU-NPs versus percentage of cell proliferation.

\section{In Vitro Hemolytic Activity}

The In vitro hemolytic activity of CU and CU-NPs was assessed as per the previously described method (36). The hemolytic activities were determined using human red blood cells (37). Briefly, fresh human erythrocytes were taken from healthy human volunteers and collected in the tubes containing EDTA $(2 \mathrm{mg} / \mathrm{ml})$ which acts as anticoagulant. The erythrocytes were harvested by centrifugation (Eppendorf Microcentrifuge 5418, Germany) for $10 \mathrm{~min}$ at $2000 \times g$ at $20^{\circ} \mathrm{C}$; the plasma was discarded and washed thrice with PBS. Afterward, the PBS was added into the pellet to achieve 10\% ( $/ v$ ) erythrocytes/PBS suspension. The $10 \%$ suspension was diluted 1:10 in PBS. From every suspension, $100 \mu \mathrm{l}$ was added to the different concentrations $(5,15,25 \mu \mathrm{M})$ of $\mathrm{CU}$ and CU-NPs. Incubation was carried out for $1 \mathrm{~h}$ at $37^{\circ} \mathrm{C}$. After incubation, the tubes were centrifuged for $10 \mathrm{~min}$ at $2000 \times \mathrm{g}$ at $20^{\circ} \mathrm{C}$ and the $150 \mu \mathrm{l}$ supernatant was taken into a microtiter plate and the absorbance was measured at $540 \mathrm{~nm}$ by using Thermo make Automatic Ex-Microplate Reader (M 51118170). Triton X-100 $(1 \%, w / v)$ was used as a positive control.
The percentage of hemolysis was calculated by the following formula:

$\%$ Hemolysis $=\frac{\text { Test compound-treated sample-Buffer-treated sample }}{1 \% \text { Triton X-100-treated sample-Buffer-treated sample }} \times 100$

\section{RESULTS}

\section{Synthesis of CU-NPs}

CU-NPs were prepared using curcumin as a stabilizing agent and $\mathrm{NaBH}_{4}$ as a reducing agent as indicated in Scheme 1. The carbonyl group of $\mathrm{CU}$ helps in the reduction as well as stabilization of Cu-NPs. The effect of concentration of CU on the size of CU-NPs is also clearly indicated in the Scheme 1. The small-sized and rod-shaped Cu-NPs observed might be due to the capping of more CU moiety over the surface of copper, whereas the irregular size of CU-NPs might be associated with the smaller degree of aggregation of CU capping.

\section{Characterization of CU-NPs}

The formation of CU-NPs was confirmed by X-ray diffraction studies (XRD) which is further supported by the FTIR and UV-visible spectroscopy. Initially, the formation of CU-NPs was ascertained by the XRD pattern of CU-NPs as shown in Fig. 1. The diffracted intensities were recorded from

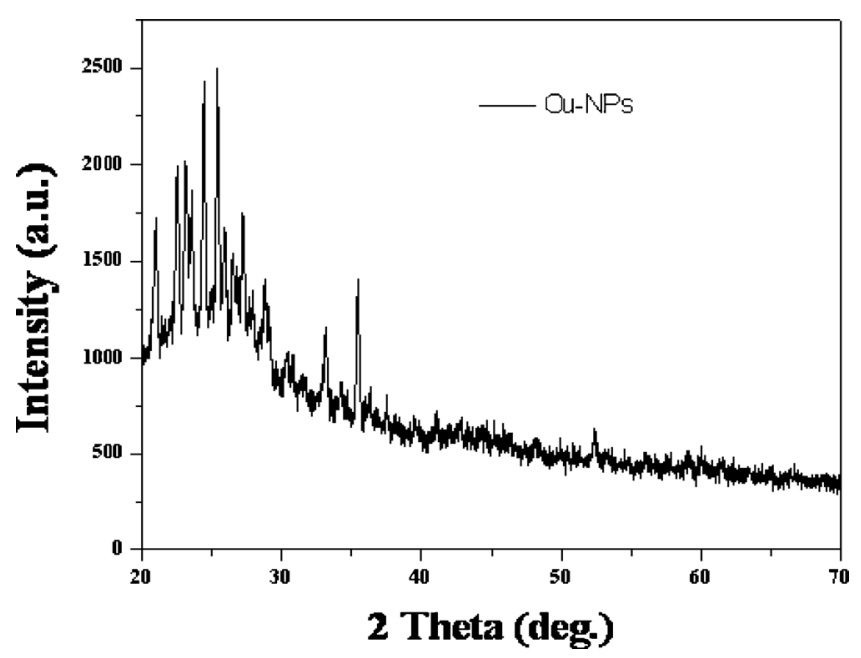

Fig. 1. X-ray diffraction pattern of CU-NPs 


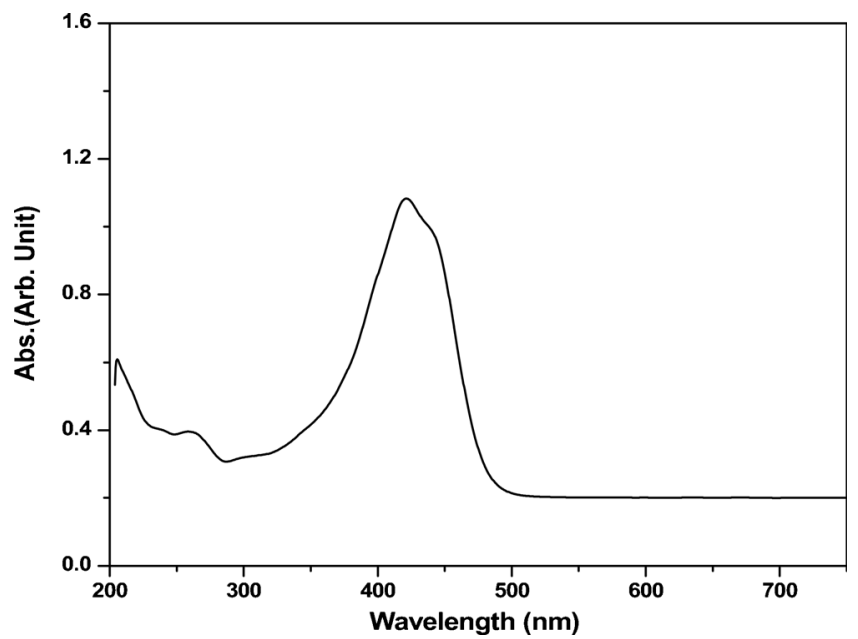

Fig. 2. UV-vis spectra of CU-NPs

$20^{\circ}$ to $70^{\circ}$. The position and relative intensity of the diffraction peaks match with the standard XRD data of copper nanoparticles (JCPDS file No. 35-0505). The $2 \theta$ peaks observed at $33.98^{\circ}$ and $35.78^{\circ}$ confirms the presence of copper nanoparticles. The X-ray diffraction pattern clearly indicates that CUNPs are in amorphous phase. Furthermore, the diffraction $2 \theta$ peaks observed in the range of $20^{\circ}$ to $30^{\circ}$ for curcumin matches with the earlier report (38).

Furthermore, these findings are in good agreement with results obtained with UV-visible spectroscopy as shown in Fig. 2. The prepared CU-NPs demonstrate an absorption peak at around $420 \mathrm{~nm}$ which indicates the formation of CU-NPs, as there is no further clearly observable and measurable peak.

Further characterization of CU-NPs was carried out by FTIR. The FTIR spectra of CU and CU-NPs are shown in Fig. 3. The broad peak at $3508 \mathrm{~cm}^{-1}$ indicates the presence of a hydroxyl group, the peak at $1726 \mathrm{~cm}^{-1}$ indicates the presence of a $\mathrm{C}=\mathrm{O}$ group (carbonyl) in the curcumin, whereas the narrowly spaced doublet at 1628 and $1600 \mathrm{~cm}^{-1}$ can be assigned to the symmetric and unsymmetrical stretching of the alkene conjugated to 1,3-diketone group. The peak at $1501 \mathrm{~cm}^{-1}$ can be assigned to the stretching vibration of the aromatic ring. The FTIR spectra of $\mathrm{Cu}-\mathrm{NPs}$ clearly indicate peak at $3501 \mathrm{~cm}^{-1}$ with the higher absorption intensity of the hydroxyl group. The formation of Cu-NPs further can be evidenced from the disintegration of peak at $1726 \mathrm{~cm}^{-1}$ which indicates the reduction of carbonyl group taking part in the encapsulation of $\mathrm{Cu}-\mathrm{NPs}$. After the encapsulation of $\mathrm{Cu}-\mathrm{NPs}$ by $\mathrm{CU}$, there is a shift in $\mathrm{C}=\mathrm{O}$ peak at $1629 \mathrm{~cm}^{-1}$ appearing as a less intense band, towards higher frequency. The increase in the frequency may be due to coordination of enolic-OH of $\mathrm{CU}$ with $\mathrm{Cu}-\mathrm{NPs}$. Characterization of CU-NPs by scanning elec-

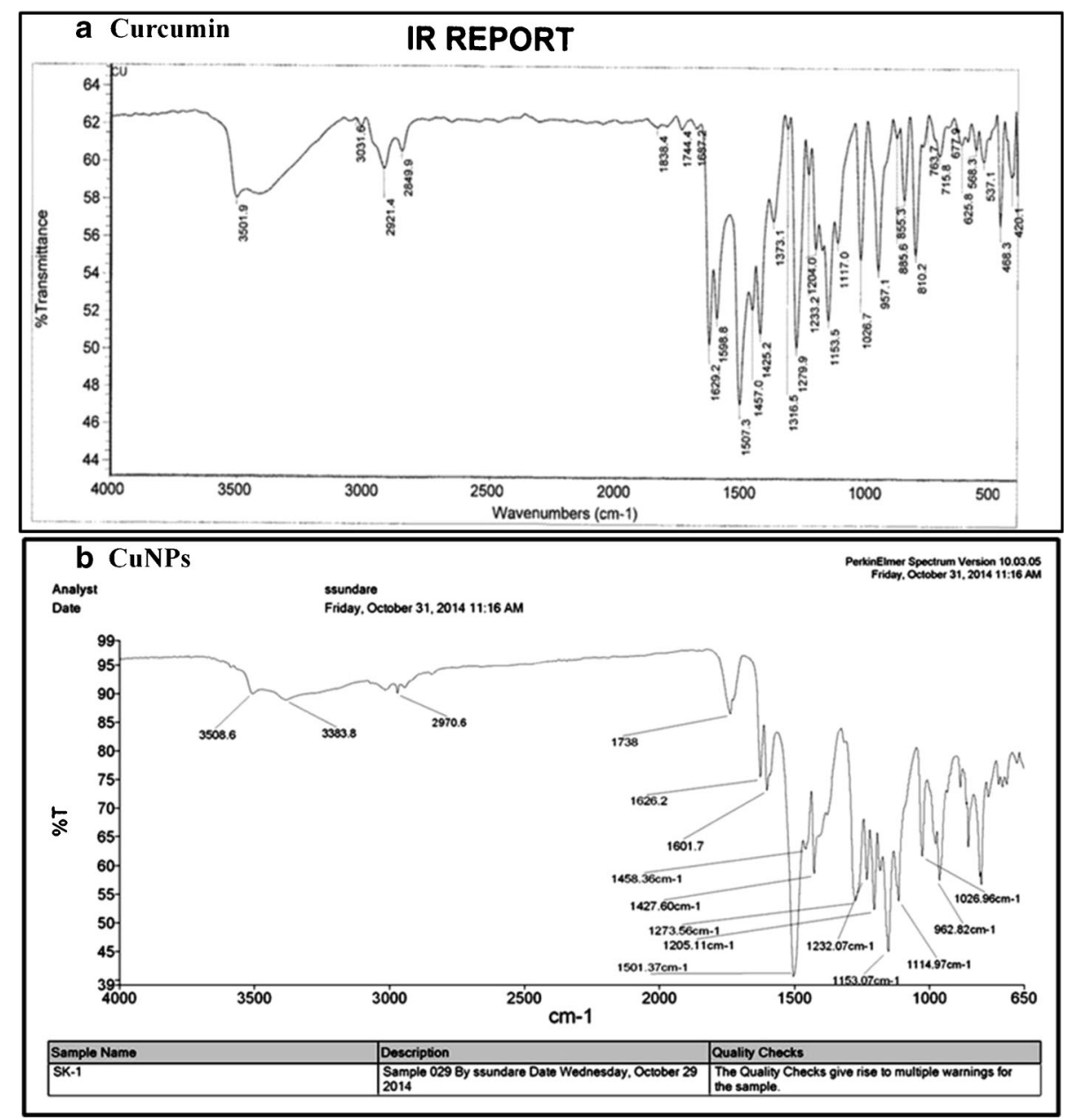

Fig. 3. FTIR Spectra of a CU and $\mathbf{b}$ CU-NPs 


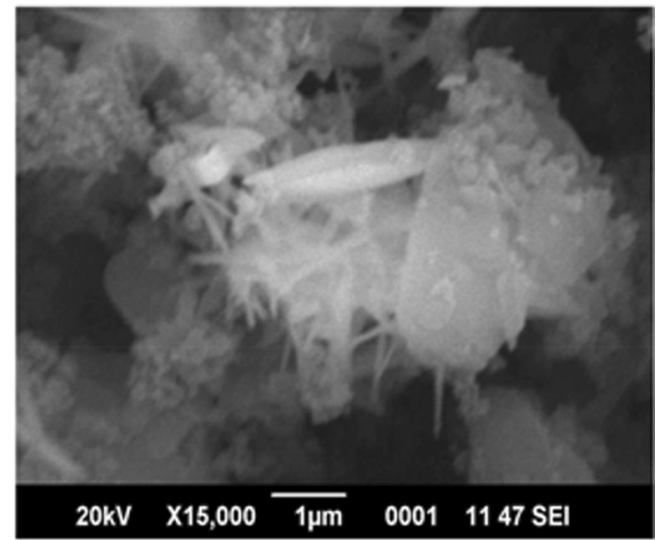

Fig. 4. SEM image of CU-NPs

tron microscopy (SEM) also supports the synthesis of nanoparticles. The morphology of nanoparticles was shown as a small rod-like structure having the quantity of patches on the surface as shown in Fig. 4. The diameter of the nanoparticles is found to be $178 \mathrm{~nm}$. Further, the nanoparticle size measurement by nanoparticle tracking and analysis system using LM 20 demonstrates that the average CU-NP size measured is $173 \mathrm{~nm}$ as the mode value (most frequent particle size) as shown in Fig. 5.

\section{Chorioallantoic Membrane Assay}

The profile of concentration-dependent antiangiogenic activities of CU and CU-NPs using the CAM model is summarized in Table I. The results obtained clearly demonstrate that $\mathrm{CU}$ was found to be more antiangiogenic as compared to CU-NPs in CAM studies. The dosedependent inhibition of angiogenesis by CU clearly demonstrates the efficacy of $\mathrm{CU}$ as an antiangiogenic agent as compared to CU-NPs in CAM model. CU showed the antiangiogenic activity in a dose-dependent manner such as $26.0 \pm 1.2 \%$ at $5 \mu \mathrm{M}, 39.0 \pm 0.97 \%$ at $15 \mu \mathrm{M}$, and 54.0 $\pm 1.5 \%$ at $25 \mu \mathrm{M}$, while CU-NPs showed the activity as $21.0 \pm 0.98 \%, 29.0 \pm 0.92 \%$, and $43.0 \pm 0.88 \%$ at 5,15 , and $25 \mu \mathrm{M}$, respectively. The control and treated CAMs were digitized using Olympus make SZ 61TR Zoom Trinocular Microscope attached with CCD camera and an image capturing software Pinnacle v. 6.0.2 (build 152) as shown in (Fig. 6). The digitized CAMs were further analyzed using image analysis software AngioQuant v 1.33 (a MATLAB-based software tool for quantification of angiogenesis) for the analysis of number, length, size, and the junctions of the tubule complexes. The results of the software analysis indicate that there was a significant reduction in the number, length, size and junctions of the tubule complexes in CU-treated CAMs as compared to treatment with CU-NPs. The representative images of CAMs exposed to different concentrations of $\mathrm{CU}$ and CU-NPs are shown in Fig. 6.

\section{Inhibition of Pro-angiogenic Cytokines Supporting Tumor Growth}

CU and CU-NPs were evaluated for inhibition of selected pro-angiogenic cytokines such as TNF $\alpha$, IGF1, VEGF, IL-6, FGFb, TGF $\beta$, EGF, and leptin. These cytokines are recognized for their inclusion in the progression of tumor development, particularly by electing extensive vasculature for the promotion of tumor growth (39). The results of cytokine inhibition using CU and CU-NPs are summarized in Table II. CU demonstrated a

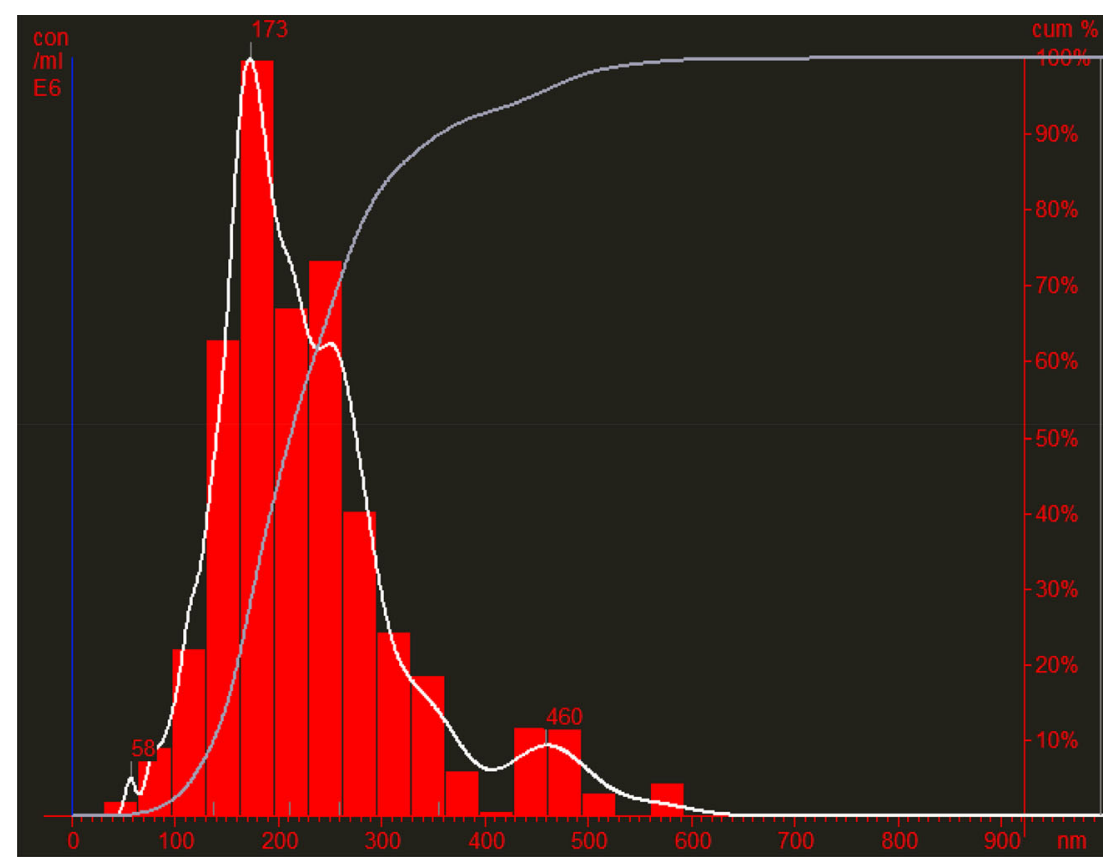

Fig. 5. Representative image of nanoparticle size measurement by LM 20 (NanoSight Ltd UK), Nanoparticle Tracking and Analysis (NTA) system. Plot representing the particle size $(\mathrm{nm})$ and concentration (particle/ml). Value 173 is mode size (in $\mathrm{nm}$ ) of observed nanoparticle 


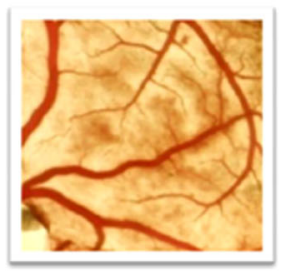

Control (PBS)

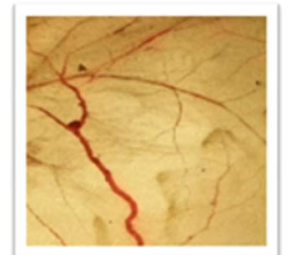

$\mathrm{CU}(5 \mu \mathrm{M})$

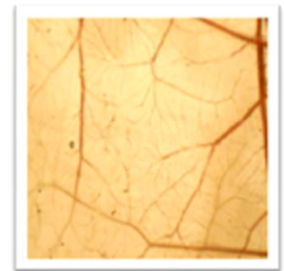

CU-NPs $(5 \mu M)$

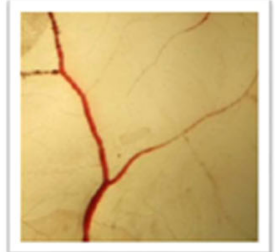

$\mathrm{CU}(15 \mu \mathrm{M})$

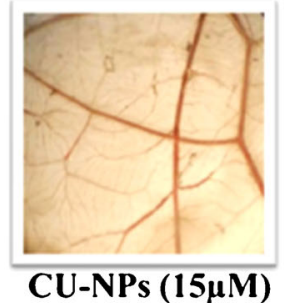

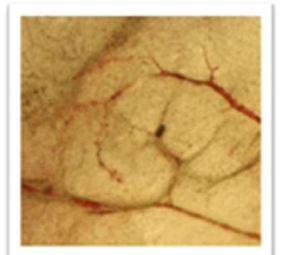

$\mathrm{CU}(25 \mu \mathrm{M})$

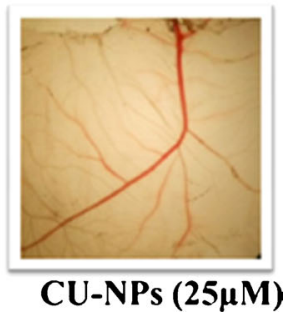

Fig. 6. Representative digitized illustrations of the CAMS exposed to different concentrations (5, $15,25 \mu \mathrm{M})$ of $\mathrm{CU}$ and CU-NPs. $\mathrm{CU}$ is showing the most promising antiangiogenic activity as compared to CU-NPs. The images of CAMS were digitized using Olympus make SZ61TR Zoom Trinocular Microscope with CCD attached camera

significant inhibition of cytokines such as TNF $\alpha$, VEGF, IL-6, and FGFb as compared to CU-NPs. Thus, the cytokine inhibition studies of CU and CU-NPs clearly demonstrate the active involvement of $\mathrm{CU}$ in inhibition of selected pro-angiogenic peptides like TNF $\alpha$, VEGF, IL-6, FGFb, and EGF as compared to CU-NPs.

\section{Cell Migration Assay}

We have examined the effect of CU and CU-NPs on the migratory behavior of a breast cancer cell line (MDA-MB 231) by performing cell migration assay. As shown in Fig. 7, the microscopic images clearly showed that $\mathrm{CU}$ considerably inhibited migration of breast cancer cells as compared to CUNPs in a dose-dependant manner. CU significantly reduced the migration of breast cancer cell line at a concentration of 5 , 15 , and $25 \mu \mathrm{M}$ over a period of $12 \mathrm{~h}$; however, as shown in Fig. 8, CU-NPs had no apparent influence on arresting the migration of breast cancer cells even after increasing its concentration. These results clearly indicate that $\mathrm{CU}$ possesses more antimigration potential as compared to CU-NPs.

\section{MTT Proliferation Assay}

We performed an MTT assay to study the effects of CU and CU-NPs on the proliferation of breast cancer cell line MDA-MB 231. Cell lines were treated with the different concentrations $(5,15,25 \mu \mathrm{M})$ of $\mathrm{CU}$ and CU-NPs for a period

Table I. Antiangiogenic Activities (\%) of CU and CU-NPs

\begin{tabular}{lllll}
\hline Sr. No. & Test samples & \multicolumn{3}{l}{ Antiangiogenic activity (\%) } \\
\cline { 3 - 5 } & & $5 \mu \mathrm{M}$ & $15 \mu \mathrm{M}$ & $25 \mu \mathrm{M}$ \\
\hline 1 & $\mathrm{CU}$ & $26.0 \pm 1.2$ & $39.0 \pm 0.97$ & $54.0 \pm 1.5$ \\
2 & $\mathrm{CU}-\mathrm{NPs}$ & $21.0 \pm 0.98$ & $29.0 \pm 0.92$ & $43.0 \pm 0.88$ \\
\hline
\end{tabular}

Results are expressed as the mean values from three independent experiments \pm standard deviation

$C U$ native curcumin, $C U$-NPs curcumin-capped copper nanoparticles of 24, 48, and 72 h. As shown in Fig. 9, breast cancer cells treated with different concentrations of $\mathrm{CU}$ resulted in the decreased cell proliferation in a dose- and time-dependent manner. As shown in Fig. 10, the growth of cells treated with different concentrations of CU-NPs resulted in the increased cell proliferation in a dose- and time-dependent manner.

\section{In Vitro Hemolytic Activity}

The hemolytic potential of CU and CU-NPs was assessed by incubating isolated erythrocytes with different concentrations of CU and CU-NPs $(5,15,25 \mu \mathrm{M})$. As shown in Fig. 11, all CU and CU-NP concentrations showed negligible hemolytic activity as compared to the positive control Triton X-100 and all were within the permissible limit of $5 \%$ for hemolysis (40).

\section{DISCUSSION}

The present work was designed to evaluate the effect of $\mathrm{CU}$ and CU-NPs on human breast cancer cells, with a clear hypothesis that CU-NPs might improve the biological activity over native CU. The synthesis of metal nanoparticle is being constantly appreciated in several preclinical model studies for the development of novel and effective anticancer agents and a strategy for effective targeted drug delivery system (41).

The most common techniques for the preparation and stabilization of metal nanoparticles are chemical, physical, and biological methods; the chemical methods such as chemical reduction, photochemical reduction, and electrochemical techniques are generally used for the preparation of nanoparticles. In the physical approach such as physical vapor condensation, arc discharge is the generally used method (42). Literature have revealed that the size, morphology, stability, and properties including chemical and physical of the metal nanoparticles are altered strongly by the experimental conditions, the kinetics of interaction of metal ions with reducing agents, and the adsorption processes of stabilizing agent with metal nanoparticles (43). Among the metal nanoparticles, copper nanoparticle synthesis is gaining momentum owing to its costeffectiveness as compared silver and gold (5). 
Table II. Effect of CU and CU-NPs on the Tumor Growth Promoting Cytokines (Growth Factors) at 0.01 mM Concentration

\begin{tabular}{|c|c|c|c|c|c|c|c|c|}
\hline \multirow[t]{2}{*}{ Sample } & \multicolumn{8}{|c|}{ Inhibition of tumor growth promoting cytokine (\%) } \\
\hline & $\mathrm{TNF} \alpha$ & IGF1 & VEGF & IL-6 & $\mathrm{FGFb}$ & TGF $\beta$ & EGF & Leptin \\
\hline \multirow[t]{2}{*}{$\mathrm{CU}$} & 85.77 & 67.45 & 88.45 & 82.66 & 81.49 & 61.37 & 71.43 & 69.79 \\
\hline & \pm 0.08 & \pm 0.06 & \pm 0.07 & \pm 0.09 & \pm 0.18 & \pm 0.10 & \pm 0.08 & \pm 0.20 \\
\hline \multirow[t]{2}{*}{ CU-NPs } & 51.58 & 42.36 & 52.49 & 45.77 & 54.66 & 43.67 & 44.74 & 39.65 \\
\hline & \pm 0.21 & \pm 0.19 & \pm 0.09 & \pm 0.04 & \pm 0.21 & \pm 0.12 & \pm 0.05 & \pm 0.10 \\
\hline \multirow[t]{2}{*}{ SURAMIN } & 89.79 & 88.64 & 93.83 & 89.57 & 90.64 & 91.81 & 87.37 & 85.46 \\
\hline & \pm 0.05 & \pm 0.03 & \pm 0.04 & \pm 0.11 & \pm 0.07 & \pm 0.04 & \pm 0.07 & \pm 0.07 \\
\hline
\end{tabular}

Results are expressed as the mean values from three independent experiments \pm standard deviation (SD)

$C U$ native curcumin, $C U$-NPs curcumin-capped copper nanoparticles, $T N F \alpha$ tumor necrosis factor alpha, $I G F 1$ insulin-like growth factor 1 , $V E G F$ vascular endothelial growth factor, $I L-6$ interleukin $6, F G F b$ fibroblast growth factor-basic, $T G F \beta$ transforming growth factor beta, $E G F$ epidermal growth factor

The metal nanoparticles are usually synthesized by controlled reduction of their particular salts in aqueous medium. It is reported that the use of excess reducing agents such as sodium citrate and sodium borohydride $\left(\mathrm{NaBH}_{4}\right)$ is the most widely recognized method for the synthesis of metal nanoparticles (42). In the current study, the nanoparticles were synthesized by the Creighton method which is the routine strategy for the synthesis of silver nanoparticles, and modifications of this method can likewise be adjusted for the synthesis of nanoparticles from different metals such as $\mathrm{Pt}, \mathrm{Pd}, \mathrm{Cu}$, $\mathrm{Ni}$, and so forth. The specific strategy is depending upon the reduction capability of the source ion. The nanoparticles synthesized by using this method generally have a tendency to aggregate and require a capping agent for stabilization. The capping agent can be directly added into the solution at the time of reduction. The shape and size of nanoparticles depend upon the reaction condition and capping agent used (44). The formation of nanoparticles was confirmed by the X-ray diffraction studies, FTIR spectral analysis, SEM analysis and nanoparticle size measurement by LM 20 (NanoSight Ltd, UK), and Nanoparticle Tracking and Analysis (NTA) system.
The NTA system offers direct visualization, sizing, and counting of particles (32).

Further, the antiangiogenic activity of CU and CU-NPs was assessed using the CAM assay. It is reported that the CAM model is a widely used in vivo model for determining the progress of angiogenesis (45). Angiogenesis is the formation of new blood vessels, and therefore, it is a vital process required for both physiological and pathological conditions (46). Angiogenesis is a fundamental perspective needed for the tumor development in cancer disease (47). Broad network of capillaries is essential to provide the nutrients and oxygen for growing tumor (47). Tumor-associated angiogenesis is intermediated by the migration and proliferation of host endothelial cells (48). Angiogenesis is regulated by the various angiogenic factors (49). Certain inducers of angiogenesis have been distinguished such as members of the fibroblast growth factor (FGF) family, vascular endothelial growth factor (VEGF), angiogenin, transforming growth factor alpha and beta (TGF $\alpha$ and TGF $\beta$ ), tumor necrosis factor alpha (TNF $\alpha)$, interleukins, chemokines, and angiopoietins (50). VEGF is the most important proangiogenic factor needed for tumor growth, invasion, and

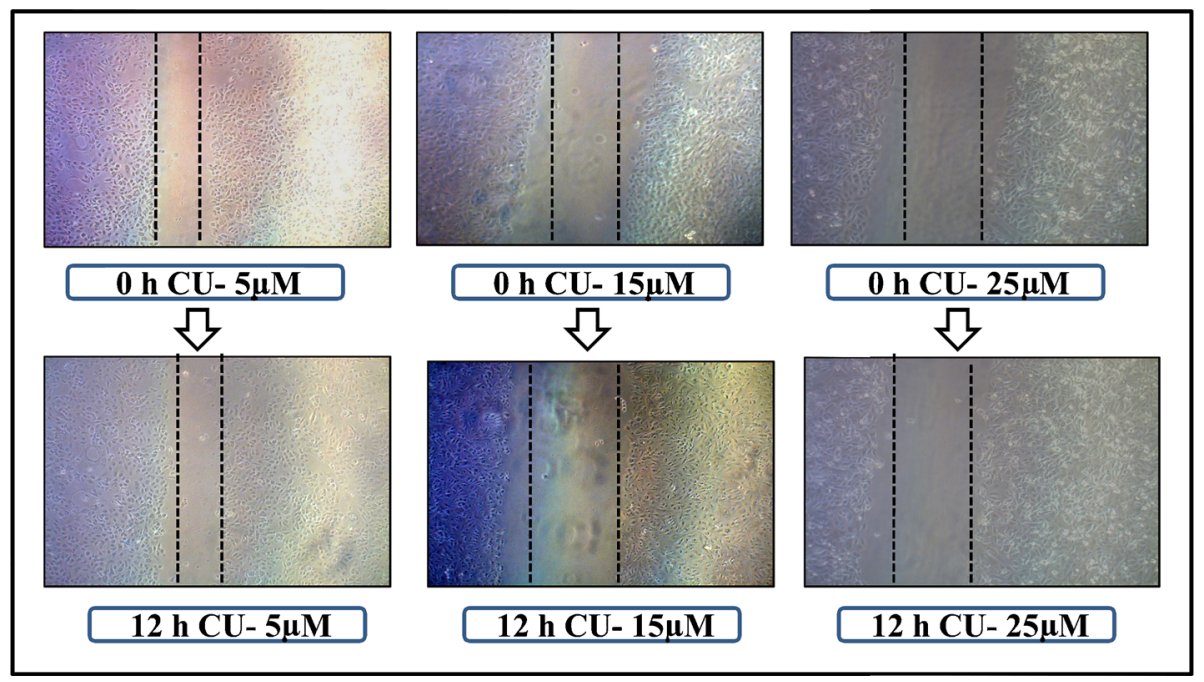

Fig. 7. Representative images showing the inhibitory effects of $\mathrm{CU}$ on breast cancer cell migration at concentrations of 5,15 , and $25 \mu \mathrm{M}$. Uniform scratches were created in cell monolayer which were treated with different concentrations of $\mathrm{CU}$ over a period of $12 \mathrm{~h}$. Images were captured at $\times 10$ magnifications using an inverted Nikon microscope equipped with digital camera 


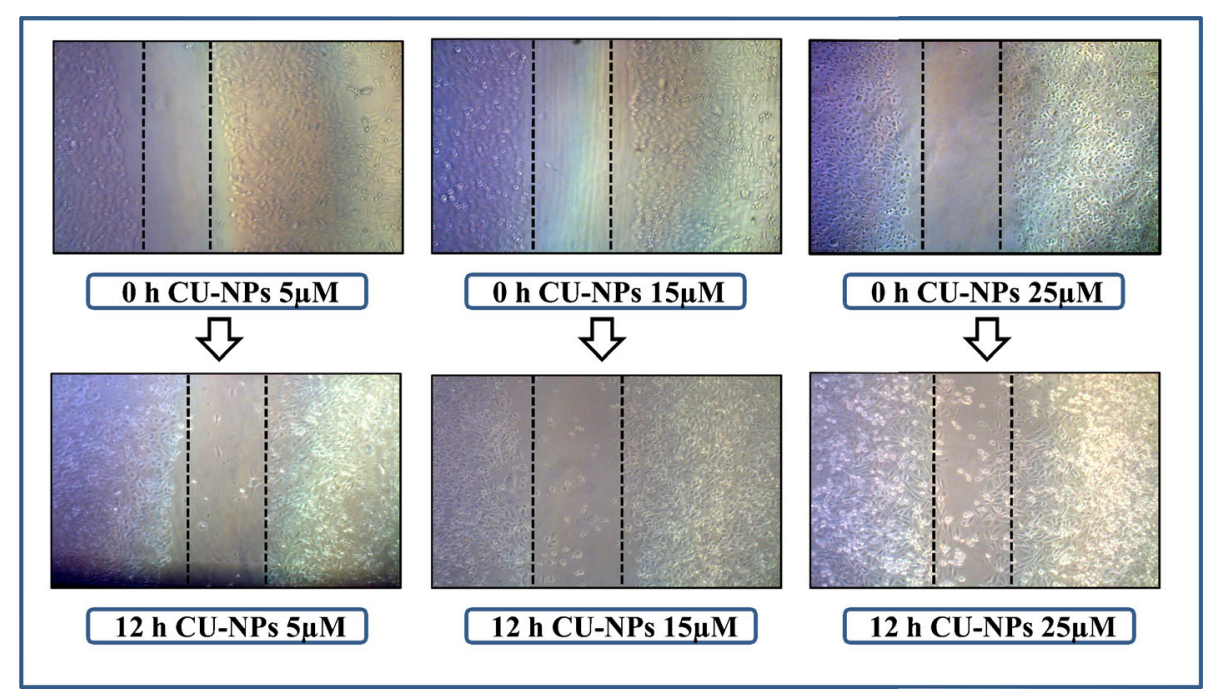

Fig. 8. Representative images of CU-NPs showing increased breast cancer cell migration at concentrations of 5,15 , and $25 \mu \mathrm{M}$. Uniform scratches were created in cell monolayer which were treated with different concentrations of CU-NPs over a period of $12 \mathrm{~h}$. Images were captured at $\times 10$ magnifications using an inverted Nikon microscope equipped with digital camera

metastasis (51). In our study, it was observed that CU was found to have more antiangiogenic potential as compared to CU-NPs in CAM studies. CU and CU-NPs were further evaluated for inhibition of selected cytokines such as TNF $\alpha$, IGF1, VEGF, IL6, FGFb, TGFß, EGF, and leptin by using Human Angiogenesis I ELISA Strip Kit for profiling of eight different cytokines. These cytokines play a vital role in promotion of tumor growth, particularly by recruiting massive vasculature (39). And the antiangiogenic study clearly demonstrates the involvement of $\mathrm{CU}$ in the inhibition process of angiogenesis by inhibiting the pro-angiogenic growth factors like TNF $\alpha$, VEGF, IL-6, FGFb, and EGF. However, CU-NPs do not demonstrate significant antiangiogenic activity. Curcumin is described as a potent inhibitor of angiogenesis. It is reported that curcumin can downregulate all positive regulators of angiogenesis including angiogenin, EGF, FGF, G-CSF, PDGF, TNF $\alpha$, and TGF $\beta$, and cytokines, such as IL-1, IL-4, IL-6, and IL-8, can act either as stimulators or inhibitors, depending on their amounts, the tumor site, and the tumor microenvironment. Moreover, curcumin has been found to regulate angiogenesis by inhibiting either the production or action of these cytokines (52).

Invasion and migration are necessities for the development and metastasis of solid tumors (53). Therefore, we have examined the effect of CU and CU-NPs on the migratory behavior of human breast cancer cells by performing cell migration assay. CU significantly reduced the migration of breast cancer cells in a concentration-dependent manner over a period of $12 \mathrm{~h}$. However, CU-NPs had no any considerable effect on arresting the migration of cells even after increasing its concentration. Previous studies have shown that $\mathrm{CU}$ has accounted to inhibit the invasion and migration of breast cancer cells by various mechanisms, such as $\mathrm{CU}$ inhibited the invasive potential of MDA-MB-231 cells by downregulation of MMP-2, MMP-3 and MMP-9 and upregulation of tissue inhibitor metalloproteinase

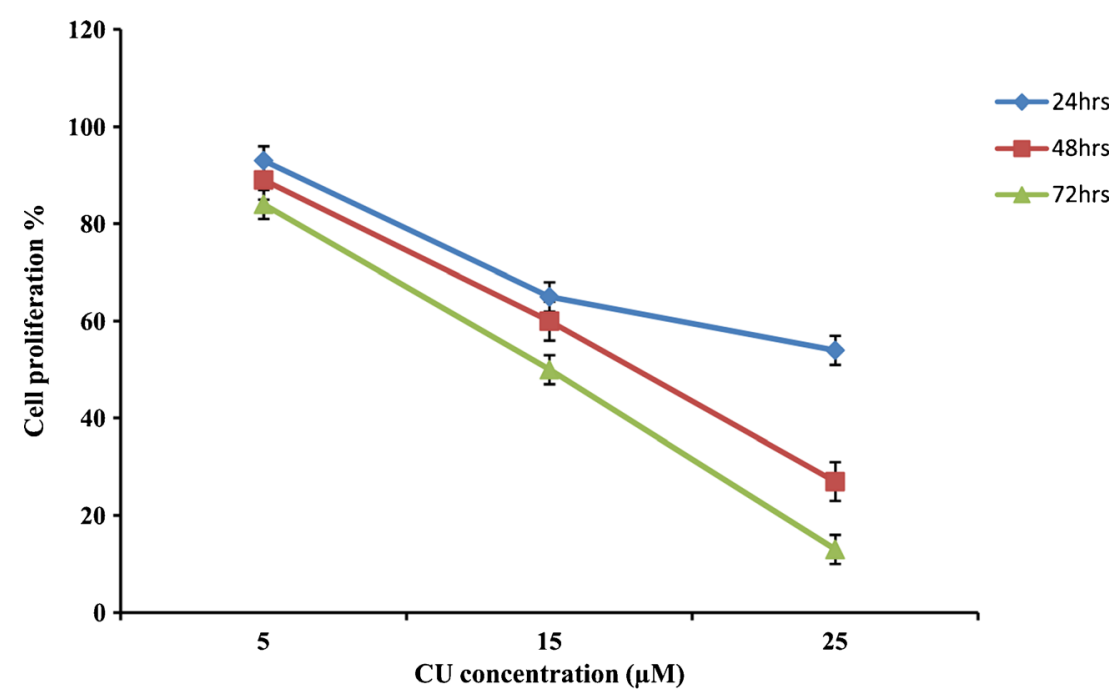

Fig. 9. MTT assay result of $\mathrm{CU}(24,48,72 \mathrm{~h}$ of treatment) showing decreased cell proliferation in a dose- and time-dependent manner. The results presented are the mean values of $n=3, \pm \mathrm{SD}$ 


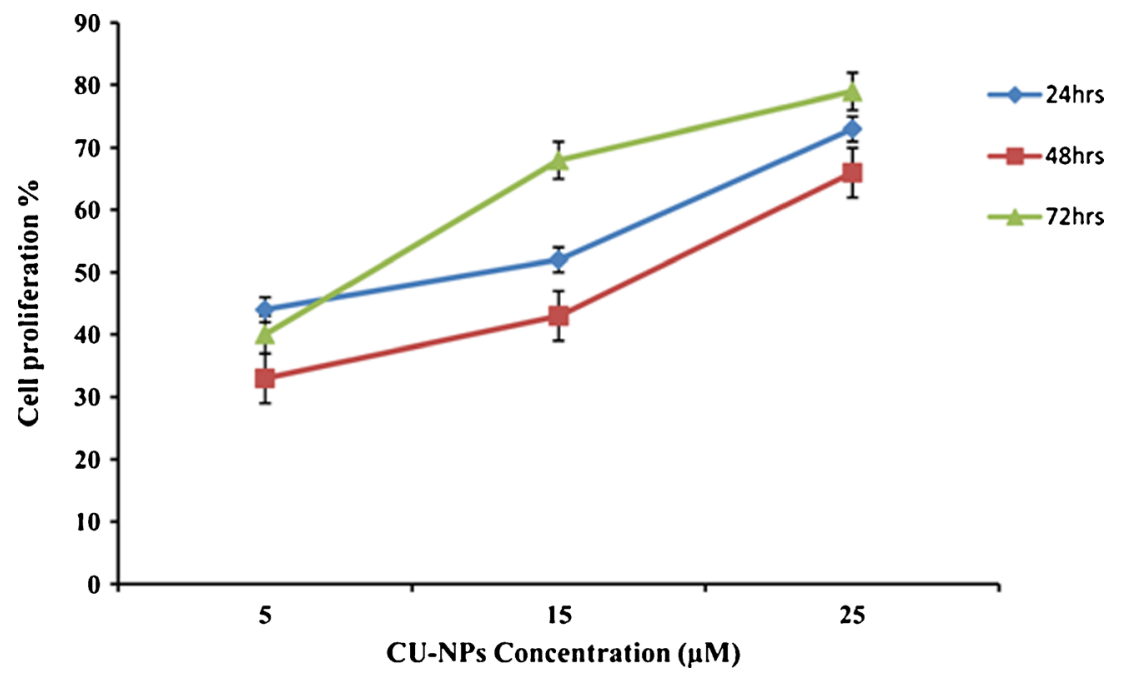

Fig. 10. MTT assay results of CU-NPs (24, 48, $72 \mathrm{~h}$ of treatment) showing increased cell proliferation in a dose- and time-dependent manner. The results presented are the mean values of $n=3, \pm \mathrm{SD}$

(TIMP-1, TIMP-2) which possibly controls tumor cell invasion (54).

We performed an MTT assay to study the effects of CU and CU-NPs on the proliferation of breast cancer cell line. The principle of the assay is that a mitochondrial enzyme in living cells, succinate dehydrogenase, cleaves the tetrazolium ring and converts the MTT to an insoluble purple formazan wherein the amount of formazan produced is directly proportional to the number of viable cells (34). Breast cancer cells treated with different concentrations of $\mathrm{CU}$ resulted in the inhibition of cell proliferation in a dose- and time-dependent manner. The growth of cells treated with different concentrations of $\mathrm{CU}$ was more significantly inhibited than the growth of cells treated with CUNPs. The literature reveled that $\mathrm{CU}$ is a potent anticancer agent because of its ability to obstruct various biochemical pathways which are associated with the proliferation of cancer cells by binding with the various targets (55).

Furthermore CU and CU-NPs were evaluated for their toxicity towards the human erythrocytes by using the in vitro hemolytic assay. Plasma hemoglobin was quantified spectrophotometrically and it was directly proportional to the concentration of lysed blood cells, which can be directly associated with the hemolytic activity of the material. The results clearly demonstrated that both CU and CU-NPs have negligible toxicity against human erythrocytes. Our results are in agreement with the previous report describing the nonsignificant hemolytic activity of CU at $0.5-100 \mu \mathrm{M}$ concentrations (40). Almost similar kind of results are reported for a variety of copper-based particles such as nano- and micron-sized copper metal particles, a nano-sized binary copper-zinc alloy, and copper oxide nanoparticles (56).

CU can bind with a broad range of molecular targets because of numerous aspects of its chemical structure (25). It is reported that $\mathrm{CU}$ is surrounded by several functional groups. The aromatic ring system which consists of two hydrophobic phenol i.e., polyphenols connected by two $\alpha$ - and $\beta$ unsaturated carbonyl group. The central diketones form stable enols or are easily deprotonated and form enolates, while the $\alpha$ - and $\beta$-unsaturated carbonyl is a Michael acceptor and

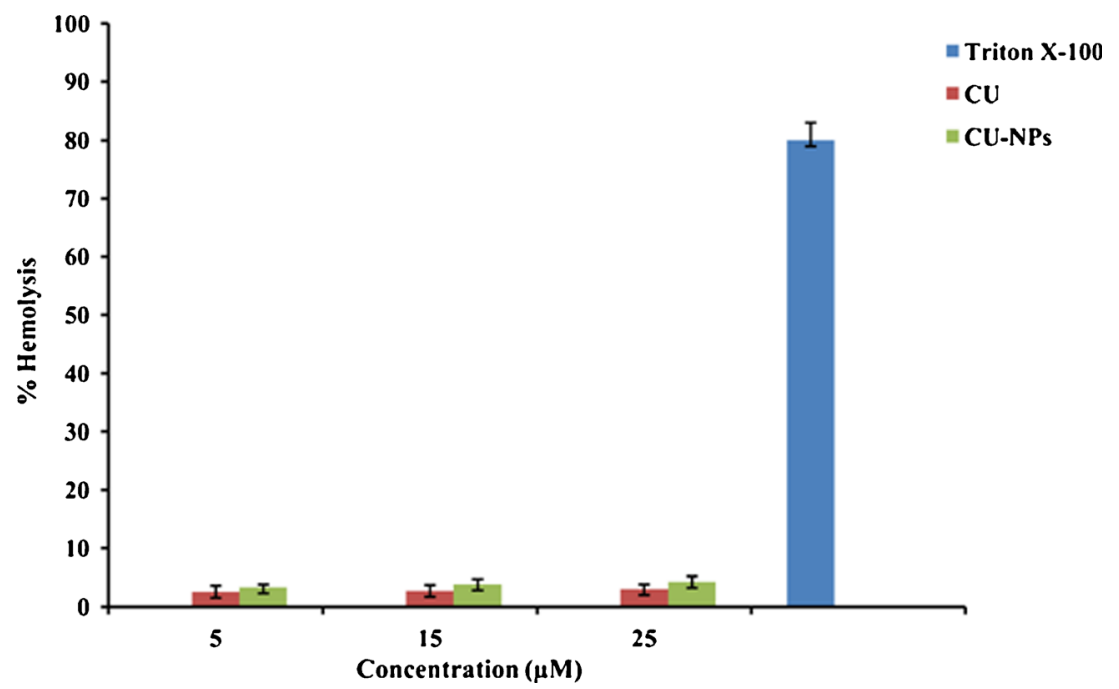

Fig. 11. Percentage of hemolysis at different concentrations of CU and CU-NPs $(5,15,25 \mu \mathrm{M})$. Triton X-100 (positive control). The results presented are the mean values of $n=3, \pm \mathrm{SD}$ 
undergoes nucleophilic addition (19). The phenolic methoxy groups, as well as the ketone and enol groups, present on the ends and in the middle of the molecule, respectively, can participate in strong hydrogen bonding interactions (57).

The reviews of literature revealed that curcumin possess a wide array of biological applications. It envisioned that copper(II) conjugate of a synthetic analogue with non-enolizable diketone is more potent than curcumin in inhibiting TNF-induced NF-kB activation and proliferation (58). Keeping this in mind, we prepared $\mathrm{Cu}-\mathrm{NPs}$ expecting the potent biological activity. But in an attempt to evaluate the effect of CU and CU-NPs on human breast cancer cells, it turned out to be an illusion; the results clearly demonstrated that the native curcumin itself is more effective against breast cancer cell line as compared to CUNPs. Our result demonstrates the efficacy of CU with promising antiangiogenic, antiproliferative, and antimigratory potential as compared to CU-NPs. While describing the possible mechanism, it has been reported that curcumin analogues particularly tetrahydro-curcumin, hexahydro-curcumin, and octahydro-curcumin are found to be less active than curcumin in suppressing NF-kB activation and tetrahydro-curcumin was found to be less active than curcumin in preventing PMA-induced skin tumor promotion in mice also due to the reduction of the carbonyl group (59). From the results, it can be stated that the presence of $\mathrm{C}=\mathrm{O}$ (carbonyl) group seems to be a key factor for the manifestation of tested biological activity of curcumin. The reduction of $\mathrm{C}=\mathrm{O}$ group due to aqueous $\mathrm{NaBH}_{4}$ might be associated with suppressing the biological activity of Cu-NPs. Indeed, the 1,3-dicarbonyl group could be considered as the pharmacophore of curcumin.

\section{CONCLUSION}

Drug conveyance frameworks utilizing nanoparticles are appreciated as a promising methodology for enhancing the safety and bioavailability of curcumin. The basic aim of the present study was to evaluate the efficacy of CU-NPs as a potential anticancer and antiangiogenic agent in concert with native CU. However, the hypothesis that CU-NPs might demonstrate the impressive anticancer and antiangiogenic activity over native CU turned out to be an illusion. Perhaps, our study is the first report of its kind, focusing the significance of synthetic methodology of nanoparticle synthesis with the biological activity. Our results signify the importance of native curcumin as a promising antiangiogenic and anticancer (against MDA-MB 231) agent as compared to its CU-NPs. It seems from the results that reduction of the carbonyl group of curcumin due to aqueous $\mathrm{NaBH}_{4}$ which is used as a common reducing agent for the synthesis of nanoparticles in the Creighton method retards the activity of $\mathrm{CU}-\mathrm{NP}_{\mathrm{S}}$. In context with the present investigation, it is indeed that the Creighton method for the synthesis of CU-NPs seems to be nonsignificant in concert with tested antiangiogenic and anticancer activities. Nanotechnology-based approaches are constantly appreciated for enhancing the biomedical applications and therapeutic index of bioactive molecules including curcumin. Therefore, there is the need to critically evaluate the nanotechnology-based approaches for maneuvering curcumin-like substances as effective bioactive molecule.

\section{ACKNOWLEDGMENTS}

The authors are thankful for the financial assistance from the University Grant Commission (F. No. 42-196/2013) (SR). They are thankful to Dr. M. S. Patole Scientist "G" NCCS, Pune, (MS), India, for his assistance throughout the research work. They thank Dr. Pandit Vidyasagar, the Honorable Vice Chancellor of S.R.T.M. University, for his kind support. SSK is sincerely thankful to UGC, New Delhi, for providing Maulana Azad National Fellowship (JRF).

\section{REFERENCES}

1. Liu D, Chen Z. The effect of curcumin on breast cancer cells. J Breast Cancer. 2013;16(2):133-7.

2. Jemal A, Siegel R, Xu J, Ward E. Cancer statistics, 2010. CA Cancer J Clin. 2010;60(5):277-300.

3. Keegan TH, Press DJ, Tao L, DeRouen MC, Kurian AW, Clarke CA, et al. Impact of breast cancer subtypes on 3-year survival among adolescent and young adult women. Breast Cancer Res. 2013;15(5):R95.

4. Chattopadhyay N, Cai Z, Kwon YL, Lechtman E, Pignol JP, Reilly RM. Molecularly targeted gold nanoparticles enhance the radiation response of breast cancer cells and tumor xenografts to X-radiation. Breast Cancer Res Treat. 2013;137(1):81-91.

5. Usman MS, Ibrahim NA, Shameli K, Zainuddin N, Yunus WM. Copper nanoparticles mediated by chitosan: synthesis and characterization via chemical methods. Molecules. 2012;17(12):14928-36.

6. Liu Y, Miyoshi H, Nakamura M. Nanomedicine for drug delivery and imaging: a promising avenue for cancer therapy and diagnosis using targeted functional nanoparticles. Int $\mathrm{J}$ Cancer. 2007;120(12):2527-37.

7. Ferrari M. Cancer nanotechnology: opportunities and challenges. Nat Rev Cancer. 2005;5(3):161-71.

8. Sperling RA, Parak WJ. Surface modification, functionalization and bioconjugation of colloidal inorganic nanoparticles. Phil Trans R Soc A. 2010;368(1915):1333-83.

9. Powell AC, Paciotti GF, Libutti SK. Colloidal gold: a novel nanoparticle for targeted cancer therapeutics. Methods Mol Biol. 2010;624:375-84.

10. Sandhu A, Handa H, Abe M. Synthesis and applications of magnetic nanoparticles for biorecognition and point of care medical diagnostics. Nanotechnology. 2010;21(44):442001.

11. Sharma H, Mishra PK, Talegaonkar S, Vaidya B. Metal nanoparticles: a theranostic nanotool against cancer. Drug Discov Today. 2015; (15) 00199-3.

12. Kleibert A, Rosellen W, Getzlaff M, Bansmann J. Structure, morphology, and magnetic properties of Fe nanoparticles deposited onto single-crystalline surfaces. Beilstein J Nanotechnol. 2011;2:47-56.

13. Rasmussen, J.W. et al. Zinc oxide nanoparticles for selective destruction of tumor cells and potential for drug delivery applications. Expert Opin. Drug Deliv. 2010;(7)1063-1077.

14. Prabhu V, Uzzaman S, Viswanathan M, Berlin G, Guruvayoorappan C. Nanoparticles in drug delivery and cancer therapy: the giant rats tail. J Cancer Ther. 2011;2:325-34.

15. Buzea C, Pacheco II, Robbie K. Nanomaterials and nanoparticles: sources and toxicity. Biointerphases. 2007;2(4):17-71.

16. Sreelakshmi CH, Goel N, Datta KK, Addlagatta A, Ummanni R, Subba Reddy BV. Green synthesis of curcumin capped gold nanoparticles and evaluation of their cytotoxicity. Nanosci Nanotechnol Lett. 2013;5(12):1258-65.

17. Bachmeier B, Nerlich AG, Iancu CM, Cilli M, Schleicher E, Vene $\mathrm{R}$, et al. The chemopreventive polyphenol curcumin prevents hematogenous breast cancer metastases in immunodeficient mice. Cell Physiol Biochem. 2007;19(1-4):137-52.

18. O'Sullivan-Coyne O'SGC, O'Donovan TR, Piwocka K, McKenna SL. Curcumin induces apoptosis-independent death in oesophageal cancer cells. British J Cancer. 2009;101(9):1585-95.

19. Aggarwal BB, Kumar A, Bharti AC. Anticancer potential of curcumin: preclinical and clinical studies. Anticancer Res. 2003;23(1A):363-98.

20. Aggarwal B, Banerjee S, Bharadwaj U, Sung B, Shishodia S, Sethi G. Curcumin induces the degradation of cyclin E expression 
through ubiquitin-dependent pathway and up-regulates cyclindependent kinase inhibitors p21 and p27 in multiple human tumor cell lines. Biochem Pharmacol. 2007;73(7):1024-32.

21. Al-Hujaily EM, Mohamed AG, Al-Sharif I, Youssef KM, Manogaran PS, Al-Otaibi B, et al. PAC, a novel curcumin analogue, has anti-breast cancer properties with higher efficiency on ER-negative cells. Breast Cancer Res Treat. 2011;128(1):97-107.

22. Reuter S, Gupta SC, Park B, Goel A, Aggarwal BB. Epigenetic changes induced by curcumin and other natural compounds. Genes Nutr. 2011;6(2):93-108.

23. Lin YG, Kunnumakkara AB, Nair A, Merritt WM, Han LY, Armaiz-Pena GN, et al. Curcumin inhibits tumor growth and angiogenesis in ovarian carcinoma by targeting the nuclear factor-kappaB pathway. Clin Cancer Res. 2007;13(11):3423-30.

24. Anand P, Thomas SG, Kunnumakkara AB, Sundaram C, Harikumar KB, Sung B, et al. Biological activities of curcumin and its analogues (Congeners) made by man and Mother Nature. Biochem Pharmacol. 2008;76(11):1590-611.

25. Salem M, Rohanib S, Gillies ER. Curcumin, a promising anti-cancer therapeutic: a review of its chemical properties, bioactivity and approaches to cancer cell delivery. RSC Adv. 2014;4:10815-29.

26. Cho K, Wang X, Nie S, Chen ZG, Shin DM. Therapeutic nanoparticles for drug delivery in cancer. Clin Cancer Res. 2008;14(5):1310-6.

27. Jantarat C. Bioavailability enhancement techniques of herbal medicine: a case example of curcumin. Pharm Pharm Scie. 2013;5:493-500.

28. Bisht S, Feldmann G, Soni S, Ravi R, Karikar C, Maitra A, et al. Polymeric nanoparticle-encapsulated curcumin ("nanocurcumin"): a novel strategy for human cancer therapy. J Nanobiotechnology. 2007;5:3.

29. Dutta AK, Ikiki E. Novel drug delivery systems to improve bioavailability of curcumin. J Bioequiv Availab. 2013;6:1.

30. Dippel V, Milde-Langosch K, Wicklein D, Schumacher U, Altevogt P, Oliveira-Ferrer L, et al. Influence of L1-CAM expression of breast cancer cells on adhesion to endothelial cells. J Cancer Res Clin Oncol. 2013;139(1):107-21.

31. Evanoff DD, Chumanov G. Synthesis and optical properties of silver nanoparticles and arrays. Chem phy schem. 2005;6(7):1221-31.

32. Filipe V, Hawe A, Jiskoot W. Critical evaluation of Nanoparticle Tracking Analysis (NTA) by NanoSight for the measurement of nanoparticles and protein aggregates. Pharm Res. 2010;27(5):796-810.

33. Birla SS, Gaikwad SC, Gade AK, Rai MK. Rapid synthesis of silver nanoparticles from Fusarium oxysporum by optimizing physicocultural conditions. ScientificWorldJournal. 2013;2013:796018.

34. Gacche RN, Shegokar HD, Gond DS, Yang Z, Jadhav AD. Evaluation of selected flavonoids as antiangiogenic, anticancer, and radical scavenging agents: an experimental and in silico analysis. Cell Biochem Biophys. 2011;61(3):651-63.

35. Sullivan R, Holden T, Tremberger G, Cheung E, Branch C, Burrero $\mathrm{J}$, et al. Fractal dimension of breast cancer cell migration in a wound healing assay. Int J Biol Life Sci. 2010;6(3):170-5.

36. Memvanga PB, Coco R, Préat V. An oral malaria therapy: curcumin-loaded lipid-based drug delivery systems combined with $\beta$-arteether. J Control Release. 2013;172(3):904-13.

37. Rajput SB, Shinde RB, Routh MM, Karuppayil SM. AntiCandida properties of asaronaldehyde of Acorus gramineus rhizome and three structural isomers. Chin Med. 2013;8(1):18.

38. Mulik RS, Mönkkönen J, Juvonen RO, Mahadik KR, Paradkar AR. Transferrin mediated solid lipid nanoparticles containing curcumin: enhanced in vitro anticancer activity by induction of apoptosis. Int J Pharm. 2010;398(1-2):190-203.

39. Gacche RN, Meshram RJ. Targeting tumor micro-environment for design and development of novel anti-angiogenic agents arresting tumor growth. Prog Biophys Mol Biol. 2013;113(2):333-54.
40. Chakrabarti R, Rawat PS, Cooke BM, Coppel RL, Patankar S. Cellular effects of curcumin on Plasmodium falciparum include disruption of microtubules. PLoS One. 2013;8(3), e57302.

41. Conde J, Doria G, Baptista1 P. Noble metal nanoparticles applications in cancer. J of Drug Delivery. 2012; 2012 (751075): 12 pages.

42. Arvizo RR, Bhattacharyya S, Kudgus RA, Giri K, Bhattacharya R, Mukherjee P. Intrinsic therapeutic applications of noble metal nanoparticles: past, present and future. Chem Soc Rev. 2012;41(7):2943-70.

43. Bekkeri S. A review on metallic silver nanoparticles. IOSR J Pharm. 2014;4(7):38-44.

44. Zhang T, Song YJ, Zhang XY, Wu JY. Synthesis of silver nanostructures by multistep methods. Sensors (Basel). 2014;14(4):5860-89.

45. Lokman NA, Elder AS, Ricciardelli C, Oehler MK. Chick chorioallantoic membrane (CAM) assay as an in vivo model to study the effect of newly identified molecules on ovarian cancer invasion and metastasis. Int J Mol Sci. 2012;13(8):9959-70.

46. Bikfalvi A, Moenner M, Javerzat S, North S, Hagedorn M. Inhibition of angiogenesis and the angiogenesis/invasion shift. Biochem Soc Trans. 2011;39(6):1560-4.

47. Potente M, Gerhardt H, Carmeliet P. Basic and therapeutic aspects of angiogenesis. Cell. 2011;146(6):873-87.

48. Gacche R, Shegokar H, Gond D, Jadhav A, Ghole V. Effect of hydroxyl substitution of flavone on angiogenesis and free radical scavenging activities: a structure-activity relationship studies using computational tools. Eur J Pharm Sci. 2010;39(1-3):37-44.

49. Abu El-Asrar AM, Nawaz MI, Kangave D, Mairaj Siddiquei M, Geboes K. Angiogenic and vasculogenic factors in the vitreous from patients with proliferative diabetic retinopathy. J Diabetes Res. 2013;2013(539658):9pages.

50. Tahergorabi Z, Khazaei MA. Review on angiogenesis and its assays. Iran J Basic Med Sci. 2012;15(6):1110-26.

51. Gacche RN, Meshram RJ. Angiogenic factors as potential drug target: efficacy and limitations of anti-angiogenic therapy. Biochim Biophys Acta. 2014;1846(1):161-79.

52. Yadav VR, Aggarwal BB. Curcumin a component of the golden spice, targets multiple angiogenic pathways. Cancer Biology \& Therapy. 2011;11(2):236-41.

53. Schneider BP, Miller KD. Angiogenesis of breast cancer. J Clin Oncol. 2005;23(8):1782-90.

54. Boonrao M, Yodkeeree S, Ampasavate C, Anuchapreeda S, Limtrakul P. The inhibitory effect of turmeric curcuminoids on matrix metalloproteinase-3 secretion in human invasive breast carcinoma cells. Arch Pharm Res. 2010;33(7):989-98.

55. kumaravel M, Sankar P, Rukkumani R. Antiproliferative effect of an analog of curcumin bis-1,7-(2-hydroxyphenyl)-hepta-1,6-diene-3,5-dione in human breast cancer cells. Eur Rev Med Pharm Scie. 2012;16:1900-7.

56. Karlsson HL, Cronholm P, Hedberg Y, Tornberg M, De Battice $\mathrm{L}$, Svedhem S, et al. Cell membrane damage and protein interaction induced by copper containing nanoparticles-importance of the metal release process. Toxicology. 2013;313(1):59-69.

57. Cridge BJ, Larsen L, Rosengren RJ. Curcumin and its derivatives in breast cancer: current developments and potential for the treatment of drug-resistant cancers. Oncology Disc. 2013;1:6.

58. Zambre AP, Kulkarni VM, Padhye S, Sandur SK, Aggarwal BB. Novel curcumin analogs targeting TNF-induced NF-kappaB activation and proliferation in human leukemic KBM-5 cells. Bioorg Med Chem. 2006;14(21):7196-2.

59. Anand P, Kunnumakkara AB, Newman RA, Aggarwal BB. Bioavailability of curcumin: problems and promises. Mol Pharm. 2008;4(6):807-18. 